\title{
Study on the infusion-site adverse events and vascular distribution of epirubicin in chemotherapy with epirubicin and fosaprepitant
}

\author{
MIHO YAMASAKI $^{1}$, RYUJI KIMURA $^{1}$, SHIGERI MAYAHARA $^{1}$, YORINOBU MAEDA ${ }^{1}$, \\ MAMORU TAKAHASHI ${ }^{2}$, TOSHIHIRO NISHIDA ${ }^{3}$, KEISUKE ODA $^{4}$ and TERUO MURAKAMI ${ }^{4}$ \\ Departments of ${ }^{1}$ Pharmacy, ${ }^{2}$ Breast Surgery and ${ }^{3}$ Diagnostic Pathology, Chugoku Rosai Hospital, Kure, \\ Hiroshima 737-0193; ${ }^{4}$ Laboratory of Biopharmaceutics and Pharmacokinetics, Faculty of Pharmaceutical Sciences, \\ Hiroshima International University, Kure, Hiroshima 737-0112, Japan
}

Received December 24, 2018; Accepted April 15, 2019

DOI: $10.3892 / \mathrm{mco} .2019 .1849$

\begin{abstract}
In breast cancer patients on a fluorouracil-epirubicin (EPI)-cyclophosphamide (FEC) regimen and intravenous fosaprepitant (FAP) during chemotherapy, infusion-site adverse events such as vascular pain and induration and/or phlebitis are observed. In the present study, adverse events induced by the FEC regimen and FAP, a prodrug of aprepitant (AP), were studied based on the vascular tissue distribution of EPI in rats. Rats were treated with intravenous FAP (3 mg/kg, 10 min-constant rate infusion) or oral $\mathrm{AP}(3 \mathrm{mg} / \mathrm{kg})$ and then intravenous EPI (1 $\mathrm{mg} / \mathrm{kg}, 5 \mathrm{~min}$-constant rate infusion) as follows: FAP-S Group, FAP and then EPI was infused from the same site on the jugular vein; FAP-D Group, FAP and then EPI was infused from different jugular veins (left and right); and AP Group, AP was administered orally and EPI was infused from the jugular vein. Concentrations of EPI in vascular tissue at the EPI infusion sites and opposite sites of the jugular vein (left and right, respectively) were measured at $30 \mathrm{~min}$ and $24 \mathrm{~h}$ after EPI infusion. Histological observation of the EPI infusion site was also made separately. In rats, the tissue concentrations of EPI at the infusion site in the FAP-S group were higher than those in the FAP-D and AP groups. Inflammation and necrosis were observed at the EPI infusion-site vascular tissue of the FAP-S group, but not
\end{abstract}

Correspondence to: Ms. Miho Yamasaki, Department of Pharmacy, Chugoku Rosai Hospital, 1-5-1 Hiro-tagaya, Kure, Hiroshima 737-0193, Japan

E-mail: m.yamasaki@chugokuh.johas.go.jp

Abbreviations: AP, aprepitant; EPI, epirubicin; FAP, fosaprepitant; FEC, fluorouracil-epirubicin-cyclophosphamide; HPLC, high performance liquid chromatography; S.D., standard deviation

Key words: adverse events, chemotherapy, drug interaction, epirubicin, fosaprepitant, vascular tissue distribution of the FAP-D and AP groups. These findings could aid the development of an approach to avoid infusion-site adverse events in anthracycline-based chemotherapy in the clinical practice.

\section{Introduction}

Chemotherapy with fluorouracil-epirubicin (EPI)cyclophosphamide, or the FEC regimen, and EPI-cyclophosphamide, or EC regimen, is widely used in breast cancer treatment. These regimens contain EPI, an anthracycline-based anti-malignant tumor drug, and are recommended to be used in combination with oral aprepitant (AP), an antiemetic drug that is a selective neurokinin-1 receptor antagonist, or intravenous fosaprepitant (FAP), a phosphorylated prodrug of AP, in clinical practice guidelines such as ASCO, MASCC/ESMO, and NCCN (1-3). AP is taken orally and FAP is administered intravenously to prevent systemic adverse events such as nausea and vomiting. Oral AP is ingested once before and twice after EPI treatment, once/day for 3 days mostly for inpatients, and intravenous FAP is administered once by constant-rate infusion over 30 min just before EPI treatment mostly for outpatients (4). It has been reported that intravenous FAP alone and an intravenous anthracycline such as doxorubicin alone can cause infusion-site adverse events (4-9). In addition, the combined use of FAP and an anthracycline is reported to induce infusion-site adverse events such as vascular pain and venous inflammation with high probability (10-12). In our hospital (Chugoku Rosai Hospital), we have experienced such infusion-site adverse events in breast cancer patients receiving chemotherapy with the FEC regimen and intravenous FAP (Proemend $^{\circledR}$, Ono Pharmaceutical Co., Ltd., Osaka, Japan) infusion. Interaction between FAP (Proemend ${ }^{\circledR}$ ) and EPI at the infusion site was suspected, as the frequency of vascular pain and venous inflammation seemed to increase after switching from oral AP (Emend ${ }^{\circledR}$, Ono Pharmaceutical Co., Ltd.) to intravenous FAP (Proemend ${ }^{\circledR}$ ). Although venous inflammation is not a serious life-threatening reaction, it disrupts the patient's quality of life (QOL) and is a major disadvantage to patients, depending on the symptoms. 
In the present study, infusion-site adverse events in chemotherapy with EPI and FAP were studied by comparing the vascular tissue concentrations of EPI and by histological observation at the EPI infusion and non-infusion sites in rats to consider a safer method in order to avoid local adverse events at the EPI infusion site.

\section{Materials and methods}

Materials. AP or Emend ${ }^{\circledR}$, and FAP dimeglumine or Proemend ${ }^{\circledR}$ Intravenous Infusion $150 \mathrm{mg}$, were obtained from Ono Pharmaceutical Co., Ltd. EPI was obtained from Nippon Kayaku Co., Ltd., (Tokyo, Japan). Other antitumor agents used were fluorouracil or Fluorouracil Injection 1,000 mg 'Towa', obtained from Towa Pharmaceutical Co., Ltd. (Osaka, Japan), and cyclophosphamide or Endoxan ${ }^{\circledR} 500 \mathrm{mg}$ for injection obtained from Shionogi \& Co., Ltd. (Osaka, Japan). All other chemicals used were of the highest purity available.

Patients and treatments. In total, eight breast cancer patients were hospitalised for chemotherapy with the FEC regimen (six advanced cancer patients) or EC regimen (two recurrent cancer patients) to treat breast cancer. Ages of the female patients ranged from 32 to 74 years and the body weights ranged from 47 to $70 \mathrm{~kg}$. AP (or Emend ${ }^{\circledR}$ ) was taken orally at a dose of $125 \mathrm{mg}$ (1st day), and $1 \mathrm{~h}$ after oral AP, the first course of chemotherapy was started by infusing EPI $\left(100 \mathrm{mg} / \mathrm{m}^{2}\right)$ in $5-10 \mathrm{~min}$, cyclophosphamide $\left(500 \mathrm{mg} / \mathrm{m}^{2}\right)$ in $30 \mathrm{~min}$, and fluorouracil $\left(500 \mathrm{mg} / \mathrm{m}^{2}\right)$ in $30 \mathrm{~min}$ for the FEC regimen, or EPI $\left(90 \mathrm{mg} / \mathrm{m}^{2}\right)$ infusion in 5-10 min and cyclophosphamide $\left(600 \mathrm{mg} / \mathrm{m}^{2}\right)$ infusion in $30 \mathrm{~min}$ for the EC regimen, respectively. On the 2nd and 3rd days, AP (or Emend ${ }^{\circledR}, 80 \mathrm{mg}$ ) alone was taken orally in both the FEC and EC regimens. Thereafter, patients were discharged from the hospital and received the following courses of the FEC or EC regimen as outpatients every 3 weeks. Each time, they received FAP dimeglumine (150 mg as FAP) by a constant-rate infusion over 30 min just before chemotherapy, in which FAP dimeglumine, or Proemend ${ }^{\circledR}$ Intravenous Infusion $150 \mathrm{mg}$, in a vial was dissolved with $100 \mathrm{ml}$ saline. Pre-operative and post-operative chemotherapy were administered for up to 4 courses, and chemotherapy for advanced and recurrent cancer was administered at up to $<900 \mathrm{mg} / \mathrm{m}^{2}$ of EPI as the cumulative amount while observing the effect.

Vascular distribution of EPI in rats. Male Sprague-Dawley (SD) rats (7-weeks-old) weighing approximately $250 \mathrm{~g}$ were obtained from Hiroshima Jikken Dobutsu Kenkyujo (or Hiroshima Institute of Experimental Animals, Hiroshima, Japan) and were maintained under a 12-h light/12-h dark cycle for at least 1 week before the experiments. The rats were anaesthetised with pentobarbital $(50 \mathrm{mg} / \mathrm{kg})$ via intraperitoneal injection and randomly divided into the following 3 groups: FAP-S Group, 10-min FAP dimeglumine infusion (3 $\mathrm{mg}$ as FAP $/ \mathrm{kg}$ ) from the left jugular vein and then 5-min EPI infusion $(1 \mathrm{mg} / \mathrm{kg})$ from the left jugular vein; FAP-D Group, 10 -min FAP dimeglumine infusion ( $3 \mathrm{mg}$ as FAP/kg) from the right jugular vein and then 5-min EPI infusion $(1 \mathrm{mg} / \mathrm{kg})$ from the left jugular vein; and AP Group, AP was administered orally $(3 \mathrm{mg} / \mathrm{kg})$ followed by 5 -min EPI infusion $(1 \mathrm{mg} / \mathrm{kg})$ from the left jugular vein after $60 \mathrm{~min}$. FAP dimeglumine (Proemend $^{\circledR}$ ) and EPI were dissolved in saline at concentrations of $1.5 \mathrm{mg}$ as $\mathrm{FAP} / \mathrm{ml}$ and $1 \mathrm{mg} / \mathrm{ml}$, respectively. The constant-rate infusion of the FAP dimeglumine solution (3 $\mathrm{mg}$ as FAP/2 $\mathrm{ml}$ saline $/ \mathrm{kg}$ ) for $10 \mathrm{~min}$ followed by the EPI solution $(1 \mathrm{mg} / \mathrm{ml} / \mathrm{kg})$ for $5 \mathrm{~min}$ was performed using the STC-525 Terumo infusion pump (Terumo Corporation Tokyo, Japan). A $26 \mathrm{G}$ needle connected to polyethylene tubing from the infusion pump was inserted into the jugular vein at approximately 7-mm length in the upward direction from a position just above the intersection of the subclavian vein and jugular vein. At $30 \mathrm{~min}$ or $24 \mathrm{~h}$ after EPI infusion, the rat abdomen was incised, and the portal vein was cut to collect a blood sample under anaesthesia. After the rat died due to blood loss, approximately $2 \mathrm{~cm}$ samples of the jugular vein at the infusion site and on the opposite site of the neck were excised. The isolated vascular tissue samples were washed gently with a small amount of ice-cold saline to remove blood and were then wiped with paper to remove water. Blood samples collected were centrifuged at $3,000 \mathrm{x} \mathrm{g}, 4^{\circ} \mathrm{C}$ for $5 \mathrm{~min}$ to obtain plasma samples. The obtained plasma and vascular tissue samples were frozen at $-80^{\circ} \mathrm{C}$ until analysis.

Histological analysis. In separate experiments, rats were treated with a two-times higher dose of each drug (EPI $2 \mathrm{mg} / \mathrm{kg}$, FAP $6 \mathrm{mg} / \mathrm{kg}$, AP $6 \mathrm{mg} / \mathrm{kg}$ ) for histological analysis than those used for the vascular tissue distribution study to increase drug pharmacological action. Rats were sacrificed at $24 \mathrm{~h}$ after EPI infusion and vascular tissue along with the surrounding tissue at the EPI infusion site and its opposite site was isolated. Vascular tissue samples were washed gently with a small amount of ice-cold saline, fixed in $15 \%$ formalin, and then embedded in paraffin. After haematoxylin-eosin staining of tissue sections of approximately $2-4-\mu \mathrm{m}$ thickness, the tissue was examined under an optical microscope (Nikon Eclipse E1000, Nikon Instech Co., Ltd.) at magnification, x200.

Analysis of EPI. Concentrations of EPI in plasma samples and vascular tissue samples were determined by high performance liquid chromatography (HPLC). The plasma sample $(200 \mu \mathrm{l})$ was mixed with an equal volume of acetonitrile $(200 \mu \mathrm{l})$, centrifuged at $10,000 \times \mathrm{g}\left(4^{\circ} \mathrm{C}\right)$ for $5 \mathrm{~min}$, and $1 \%$ acetic acid $(80 \mu \mathrm{l})$ was added to the supernatant $(120 \mu \mathrm{l})$. The vascular tissue sample (about $20 \mathrm{mg}$ ) was weighed and homogenised in a 19 -fold volume of $50 \%$ acetonitrile by ultrasonic treatment (Tomy UD-201, Tomy Seiko Co., Ltd., Tokyo, Japan) for approximately $2 \mathrm{~min}$. The suspension was centrifuged at $10,000 \times \mathrm{g}\left(4^{\circ} \mathrm{C}\right)$ for $5 \mathrm{~min}$, and a mixture of $1 \%$ acetic acid (40 $\mu \mathrm{l})$ and HPLC mobile phase (100 $\mu \mathrm{l}$ of a mixture of $0.1 \%$ acetic acid and acetonitrile, 7:3) for EPI analysis was added to the supernatant $(60 \mu \mathrm{l})$. The suspension was filtered with a $0.45 \mu \mathrm{m}$-syringe filter, and the filtrate was subjected to EPI analysis by HPLC. The HPLC column used was a YMC-Triart C18 column (150x4.6 mm I.D.; YMC Inc., Kyoto, Japan). The mobile phase was a mixture of $1 \%$ acetic acid and acetonitrile in a ratio of 7:3 (v/v), and the flow rate was set at $1.0 \mathrm{ml} / \mathrm{min}$. EPI was detected fluorometrically at an excitation wavelength of $470 \mathrm{~nm}$ and an emission wavelength of $585 \mathrm{~nm}$. The obtained calibration curve was linear in a concentration range from $2 \mathrm{ng}$ to $500 \mathrm{ng} / \mathrm{ml}$ and from 1 to $10 \mu \mathrm{g} / \mathrm{ml}$. 


\section{Case\#1}

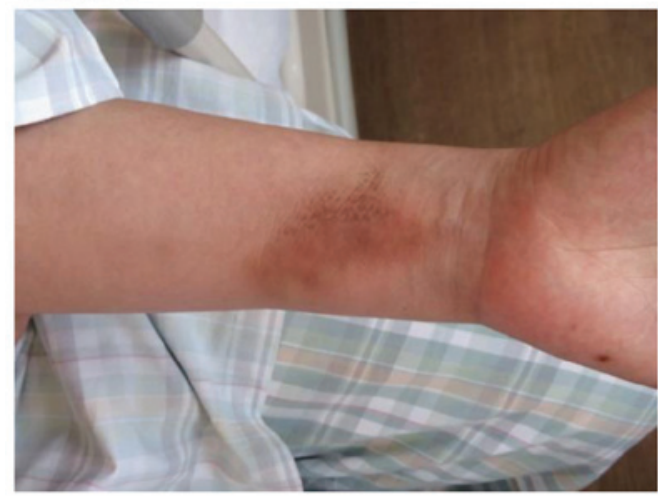

Case\#2

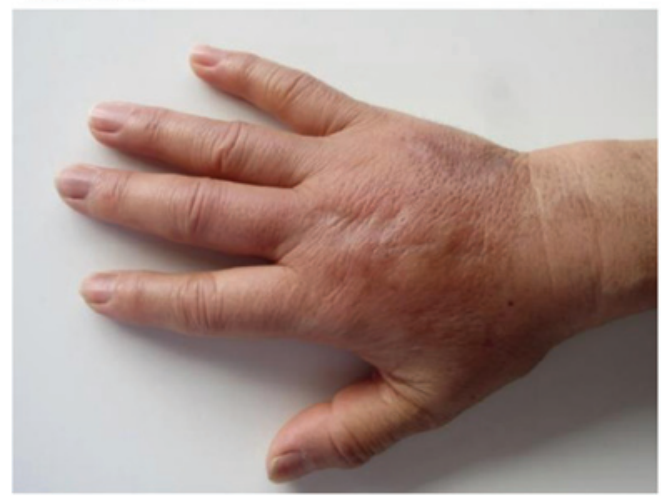

Figure 1. Induction of grade-2 infusion-site adverse events in breast cancer chemotherapy with the FEC regimen together with intravenous FAP (Proemend ${ }^{\circledR}$ ) infusion. Case \#1: Grade 2 induration at the EPI infusion site inside the wrist observed after the 4th course of FEC chemotherapy. Case \#2: Grade 2 phlebitis at the EPI infusion site on the back of the hand observed after the 3rd course of FEC chemotherapy. EPI, epirubicin; FEC, fluorouracil-epirubicin-cyclophosphamide; FAP, fosaprepitant.

Statistical analysis. The data are presented as the mean \pm S.D. $(n=4)$, and statistical analysis was performed by one-way ANOVA, followed by the Tukey-Kramer method for multiple comparisons. $\mathrm{P}<0.05$ was considered to indicate a statistically significant difference.

\section{Results}

Chemotherapy for breast cancer patients. After single oral administration of AP, chemotherapy with the FEC regimen or EC regimen was started in 8 breast cancer patients. After the first course of chemotherapy, AP was administered for 2 more days. The patients left the hospital and the following course of chemotherapy was performed as outpatients by intravenous infusion of FAP dimeglumine just before the following course of chemotherapy. Before starting the 2nd course of chemotherapy, none of the patients admitted any side effects on the skin. After starting the 2nd or 3rd course of chemotherapy, 5 patients out of 8 complained of vascular pain and 3 patients among them showed angitis at the EPI infusion site. In addition, 2 patients of expressed grade 2 injection site reactions that corresponded to the common terminology criteria for the adverse events version 4.0 as follows (Cases \#1 and \#2):

Case \#1. A female breast cancer patient (45 years old weighing $59.8 \mathrm{~kg}$ ) received FEC chemotherapy. Although vascular pain appeared after the $3 \mathrm{rd}$ course of treatment, the 4th course of treatment was performed according to the initial schedule plan. Thereafter, grade 2 induration appeared at the infusion site (inside the wrist) (Fig. 1).

Case \#2. A female breast cancer patient (74 years old weighing $55.5 \mathrm{~kg}$ ) received FEC chemotherapy. After the 2nd course of chemotherapy, vascular pain, swelling, and induration appeared at the infusion site (back of the hand). After the 3rd course, phlebitis (grade 2) appeared at the infusion site, and FEC chemotherapy was discontinued and changed to other drugs (trastuzumab and docetaxel) (Fig. 1).

These results suggested the incidence of an interaction between FAP dimeglumine and EPI, since the frequency of induction of adverse events such as vascular pain and phlebitis seemed to be increased after switching to intravenous FAP dimeglumine from oral AP in clinical practice.

Vascular tissue distribution of EPI in rats. At $30 \mathrm{~min}$ and $24 \mathrm{~h}$ after the 5-min constant-rate EPI infusion, concentrations of EPI in plasma and vascular tissue were compared among the FAP-S, FAP-D, and AP groups. There was no significant difference in the plasma EPI concentrations at $30 \mathrm{~min}$ among the three different groups, and EPI was not detected in the plasma at $24 \mathrm{~h}$ after EPI infusion (Table I). The average concentrations of EPI in vascular tissue at the EPI infusion site at $30 \mathrm{~min}$ and $24 \mathrm{~h}$ were in the following order: FAP-S group $>$ FAP-D group $>$ AP group (Fig. 2A and B). In particular, the vascular tissue concentrations of EPI at $24 \mathrm{~h}$ were almost the same as those at $30 \mathrm{~min}$ in each group, irrespective of the disappearance of EPI from plasma. This indicates that EPI can accumulate in vascular tissue. A significant difference was detected in vascular tissue EPI concentrations between the FAP-S and AP groups at $24 \mathrm{~h}(\mathrm{P}<0.05)$. Infusion-site vascular tissue of EPI showed higher EPI concentrations than those in the opposite-site (or non-infusion-site) vascular tissue in all three groups. Collectively, the FAP-S group showed the highest vascular tissue concentrations of EPI at the EPI infusion site compared to those of the FAP-D group, AP group, and the non-infusion sites of all three groups at $30 \mathrm{~min}$ and $24 \mathrm{~h}$ after EPI infusion (Fig. 2).

Histological examination of vascular tissue in rats. At $24 \mathrm{~h}$ after EPI infusion, the vascular tissue at the infusion site was examined histologically by microscopic observation. The vascular endothelial cells at the EPI infusion site of the FAP-S group showed infiltration of neutrophils and necrosis, and the necrosis spread to the surrounding tissue of the EPI infusion-site jugular vein (Fig. 3A and B). The FAP-D group showed swelling of vascular endothelial cells at the EPI infusion site, but neither necrosis nor inflammation was observed (Fig. 3C). The infusion site of FAP in the FAP-D group showed no significant histological alteration in the vascular tissue (Fig. 3D). The AP group also showed no 
Table I. Concentrations of EPI in plasma and vascular tissue at the infusion-site after constant-rate EPI infusion over 5 min in rats.

\begin{tabular}{lccc}
\hline Sample (sampling time) & $\begin{array}{c}\text { FAP-S group } \\
(\mathrm{ng} / \mathrm{ml} \text { or } \mu \mathrm{g} / \mathrm{g})\end{array}$ & $\begin{array}{c}\text { FAP-D group } \\
(\mathrm{ng} / \mathrm{ml} \text { or } \mu \mathrm{g} / \mathrm{g})\end{array}$ & $\begin{array}{c}\text { AP group } \\
(\mathrm{ng} / \mathrm{ml} \text { or } \mu \mathrm{g} / \mathrm{g})\end{array}$ \\
\hline Plasma (30 min) & $9.10 \pm 2.40$ & $10.8 \pm 2.88$ & $6.47 \pm 3.06$ \\
Plasma (24 h) & $\mathrm{ND}$ & $\mathrm{ND}$ & $\mathrm{ND}$ \\
Vascular tissue (30 min) & $2.30 \pm 1.85$ & $0.958 \pm 0.767$ & $0.659 \pm 0.751$ \\
Vascular tissue (24 h) & $3.86 \pm 2.76^{\mathrm{a}}$ & $0.762 \pm 0.997$ & $0.281 \pm 0.339$ \\
\hline
\end{tabular}

FAP-S Group: FAP and EPI were infused from the same site on the jugular vein. FAP-D Group: FAP and EPI were infused from different jugular veins, respectively. AP Group: AP was administered orally and EPI was infused from the jugular vein. Each value represents the mean \pm standard deviation $(n=4)$. ${ }^{a}$ Vascular tissue concentrations of EPI in the FAP-S group at $24 \mathrm{~h}$ were significantly greater than those in the AP group at a level of $\mathrm{P}<0.05$. ND, not detected; EPI, epirubicin; FAP, fosaprepitant; AP, aprepitant.

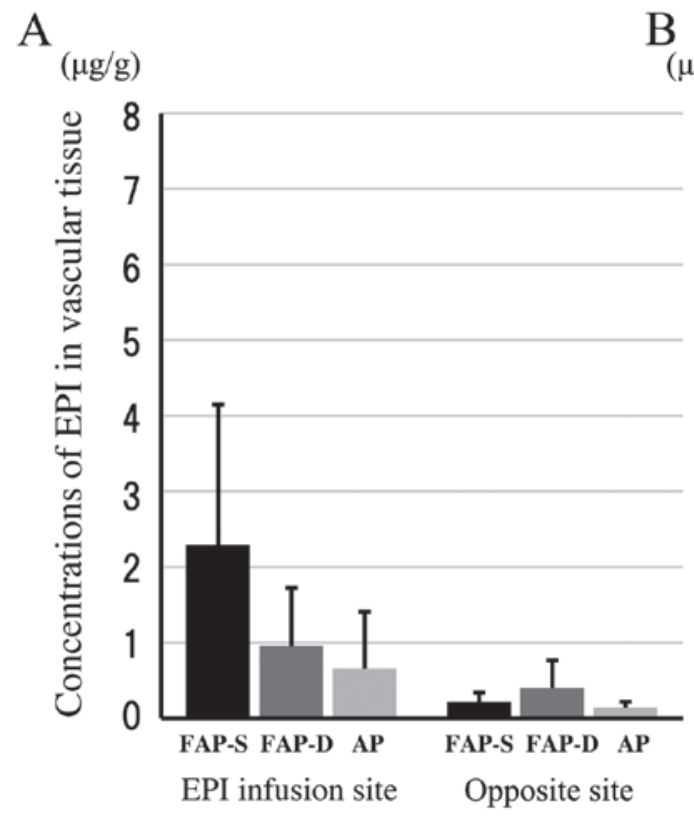

B

$(\mu \mathrm{g} / \mathrm{g})$

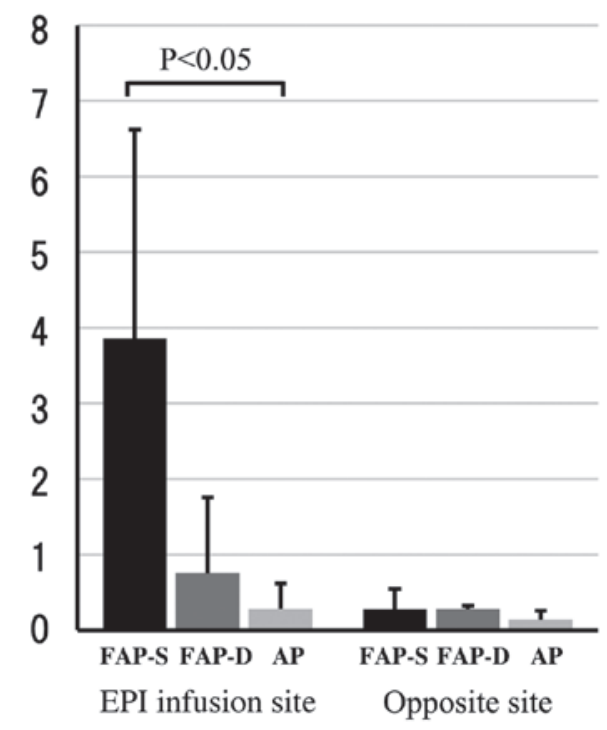

Figure 2. Concentrations of EPI in vascular tissue. Concentrations of EPI in vascular tissue at the infusion site at (A) 30 min and (B) 24 h after 5 min-EPI infusion in rats. FAP-S Group: FAP and then EPI were infused from the same site on the left jugular vein. FAP-D Group: FAP and then EPI were infused from the right and left jugular vein, respectively. AP Group: AP was administered orally and then EPI was infused from the left jugular vein. Opposite site, the right jugular vein. Each value represents the mean \pm standard deviation $(n=4)$. EPI, epirubicin; FAP, fosaprepitant.

significant alteration in the vascular tissue even at the EPI infusion site (Fig. 3E). Collectively, the magnitude of histological damage at infusion-site adverse events was in the following order: EPI-infusion site of the FAP-S group $>$ EPI-infusion site of the FAP-D group $\gg$ EPI-infusion site of the AP group and FAP-infusion site of the FAP-D group (no damage).

\section{Discussion}

When cancer cells are found in patients, cancer cells are thought to have already spread to other parts of the body through blood and lymphatic vessels in the case of invasive breast cancer. It is not easy to detect micro-metastasis of cancer cells in other tissues by diagnostic imaging and to remove them by operation. Chemotherapy is essential in addition to operation in the treatment of invasive breast cancer, and chemotherapy for breast cancer has been proven equivalent in terms of survival and overall disease progression in both pre-operative and post-operative stages (13). However, in the case of postoperative chemotherapy, there is a possibility of causing lymphedema in patients who received lymph node dissection or sentinel lymph node biopsy. Intravenous injection of anticancer drugs from the affected lymph node side should be avoided in such patients. In cancer chemotherapy, incidence of adverse events such as nausea and vomiting that decrease the patient's QOL is common and has significant effects on subsequent chemotherapy. Antiemetic guidelines such as ASCO, MASCC/ESMO, and NCCN were set up in response to the risk of cancer chemotherapy (1-3).

Chemotherapies with FEC and EC regimens containing EPI are widely performed in breast cancer treatment, and the use of dexamethasone, 5-HT3 antagonists, and AP or FAP is recommended in any of the guidelines to decrease the incidence of systemic adverse events. However, intravenous FAP 

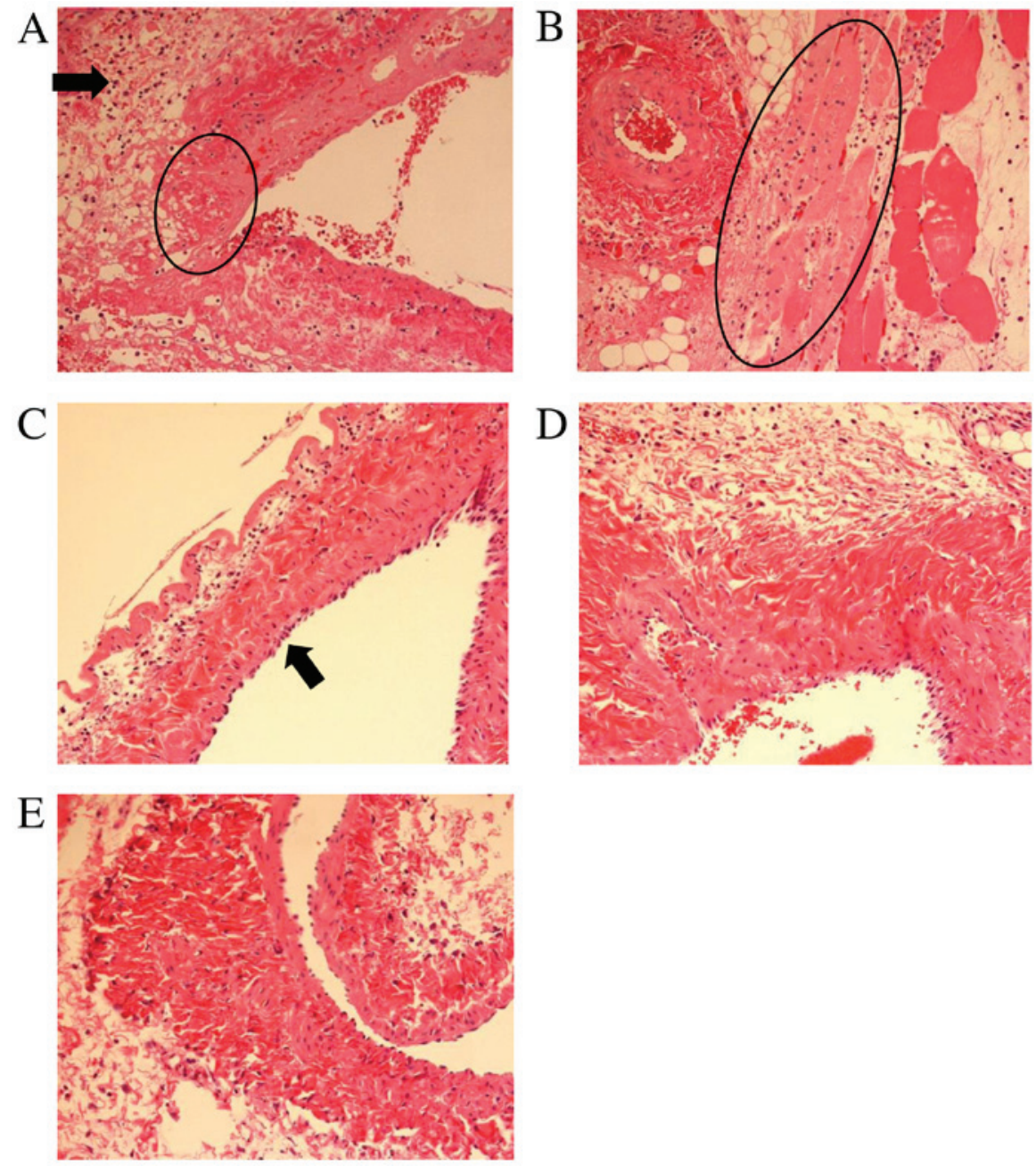

Figure 3. Histological observation of vascular tissue at the infusion site at $24 \mathrm{~h}$ after 5 min-EPI infusion in rats. (A) Vascular tissue at the EPI infusion site of the FAP-S group. Arrow shows the infiltration of neutrophils and the circle represents the vascular tissue necrosis. (B) Necrosis in tissue surrounding the EPI infusion site of the FAP-S group. The circle represents the vascular tissue necrosis. (C) Swelling of vascular endothelial cells at the EPI infusion site of the FAP-D group. Arrow head shows the swelling. (D) Neither necrosis nor inflammation was observed in the vascular tissue at the FAP infusion site of the FAP-D group. (E) Neither necrosis nor inflammation was observed in vascular tissue at the EPI infusion site of the AP group. Magnification, x200. EPI, epirubicin; FAP, fosaprepitant

infusion may be associated with a higher risk of infusion-site adverse events than AP when combined with an anthracycline in chemotherapy $(14,15)$. In contrast, the incidence of infusion-site adverse events is reportedly low when FAP infusion is combined with cisplatin-based chemotherapy, suggesting the contribution of some interaction between FAP (or Proemend ${ }^{\circledR}$ ) and anthracyclines such as doxorubicin and EPI (15).

We also experienced the incidence of infusion-site adverse events such as grade- 2 induration and grade- 2 phlebitis in addition to vascular pain in 2 breast cancer patients who received FEC chemotherapy, in which they received intravenous infusion of FAP (or Proemend ${ }^{\circledR}$ ) and 3 anticancer drugs (EPI, cyclophosphamide, and fluorouracil) serially from the same site on the vein (Fig. 1). The most common FAP infusion-site adverse events in doxorubicin/cyclophosphamide (AC) chemotherapy for 98 breast cancer patients were reported to be infusion site pain $(n=26)$, erythema $(n=22)$, swelling $(n=12)$, superficial thrombosis $(n=8)$, infusion site hives $(n=5)$, and phlebitis/thrombophlebitis $(n=5)$, where 26 patients experienced more than one type of infusion-site adverse events (11). The mechanism of the interaction between
FAP (or Proemend ${ }^{\circledR}$ ) and anthracyclines at the infusion site is not yet clarified. The injection site reaction was reported to be significantly reduced from 28.7 to $5.74 \%$ when FAP (or Proemend $^{\circledR}$ ) was diluted from $150 / 150$ to $150 \mathrm{mg} / 250 \mathrm{ml}$ and infused over $30 \mathrm{~min}$ (9). Though such a reaction caused by FAP alone or EPI alone was not observed histologically in the present study (Fig. 3), the above report regarding the reduction of infusion rate (9) suggests that the distribution of anticancer drug(s) into the infusion-site vascular tissue from blood (or plasma) circulation could be involved in infusion site adverse events. EPI with cytotoxicity is known to have a large distribution volume in rats and human and distributes to various tissues with an inter-organ variation (16-18). In contrast, cisplatin with a low incidence of infusion-site adverse events has a relatively small tissue distribution volume of approximately $20 \%$ body weight, which corresponds to the volume of plasma and intercellular space not including the intracellular aqueous space, in the body (19).

In the present study, therefore, we examined the induction mechanism of infusion-site adverse events in chemotherapy with FAP and EPI from the viewpoint of EPI distribution into 
infusion-site vascular tissue using rats. The doses of intravenous EPI (1 or $2 \mathrm{mg} / \mathrm{kg}$ ) used for the vascular tissue distribution study (Table I, Fig. 2) and histological analysis study (Fig. 3), respectively, were lower than those used in clinical FEC chemotherapy (approximately $3 \mathrm{mg} / \mathrm{kg}$ ). The infusion period (5 min) of EPI performed in the present study was close to that used in clinical chemotherapy (5-10 min). In contrast, the infusion rate (10 min-infusion) of FAP conducted in the present animal study was faster than that used in clinical chemotherapy (over $30 \mathrm{~min}$ ), though the actual drug concentration in blood circulation at the infusion site varied depending on the physiological blood stream velocity at anatomically different positions. It is not easy to adjust the local concentrations of infused drugs in the infusion-site blood stream appropriately between animal studies and clinical practice.

In the FAP-S group, FAP and EPI were administered intravenously from the same position on the jugular vein. In the FAP-D group, FAP and EPI were administered intravenously from different jugular veins, and in the AP group, AP was administered orally, and EPI was administered intravenously into the jugular vein. The EPI infusion site of the FAP-S group showed greater EPI concentrations in vascular tissue at $30 \mathrm{~min}$ and $24 \mathrm{~h}$ after EPI infusion than those in other cases including the FAP-D group, AP group, and opposite non-infusion sites (Table I, Fig. 2), suggesting that FAP (or Proemend ${ }^{\circledR}$ ) contains some components that enhance the vascular distribution of EPI. In addition, the FAP-S group alone showed inflammation and necrosis at the infusion-site vascular tissue in which necrosis had spread to the peripheral surrounding tissues (Fig. 3). In contrast, such inflammation at the vascular tissue was not observed in the FAP-D and AP groups in the present study, even though it was reported that FAP alone and EPI alone can cause infusion site adverse events (4-9). In clinical practice, complaints of vascular pain from patients also appeared after switching from oral AP to intravenous FAP. Collectively, higher vascular tissue concentrations of EPI were thought to result in inflammation and necrosis at the infusion site, and an increase in EPI distribution into vascular tissue was thought to be induced by the combined use of intravenous FAP (or Proemend ${ }^{\circledR}$ ) (Fig. 2). Regarding the tissue accumulation of EPI over a longer period (more than $24 \mathrm{~h}$ as shown in Fig. 2), irrespective of the disappearance of EPI from plasma at $24 \mathrm{~h}$ (Table I), the presence of some component(s) affecting the accumulation of EPI, a weakly basic drug with $\mathrm{pKa}=7.77$, in tissue was suspected as observed with some other weakly basic drugs (20). Further studies are necessary regarding the tissue distribution mechanism of EPI, in the presence and absence of FAP (or Proemend ${ }^{\circledR}$ ), including the tissue binding components and interorgan variation as reported (16-18).

Proemend ${ }^{\circledR}$ Intravenous Infusion $150 \mathrm{mg}$ contains FAP dimeglumine $245.3 \mathrm{mg}$ (or $150 \mathrm{mg}$ as FAP), $5.7 \mathrm{mg}$ sodium edetate hydrate, $78.8 \mathrm{mg}$ polysorbate 80 , and so on as additives in a single vial, and its contents are dissolved carefully by adding 100-150 ml saline for clinical use (21). Recently, considering that polysorbate 80 , a synthetic non-ionic surfactant, is associated with treatment-emergent adverse events, a polysorbate 80-free aprepitant IV formulation (HTX-019) was developed. HTX-019 showed bioequivalence to commercially available FAP infusion solution (Proemend ${ }^{\circledR}$ ) with a low risk of polysorbate 80 surfactant-associated systemic hypersensitivity and infusion-site adverse events (22-24). For example, the incidence of infusion-site pain caused by HTX-019 $(n=99)$ and Proemend ${ }^{\circledR}$ $(n=100)$ was 1 and 9\%, respectively (22). In our study, the EPI concentration in vascular tissue was relatively low, and no significant histological damage was observed in vascular tissue when EPI was infused from different jugular veins from FAP $\left(\right.$ Proemend ${ }^{\circledR}$ ). Taken together, these results imply the contribution of polysorbate 80 in increased vascular tissue distribution of EPI and infusion-site adverse events when FAP (Proemend ${ }^{\circledR}$ ) and EPI are infused from the same position of the blood vessel (FAP-S group). The enhancing tendency of Proemend ${ }^{\circledR}$ on the vascular tissue distribution of EPI was also observed in the FAP-D group, in which the vascular concentration of FAP (or Proemend $^{\circledR}$ ) in the opposite jugular vein from the EPI infusion site was the same as that in the EPI infusion site of the FAP-S group. The average vascular tissue concentration of EPI 30 min after administration was in the following order: FAP-D $>$ FAP-S $>$ oral AP, although there was no significant difference among the 3 groups (Fig. 2A). Further studies are necessary to clarify the induction mechanism of EPI infusion-site adverse events in detail, including the enhancing mechanism of FAP (or Proemend ${ }^{\circledR}$ ) on tissue distribution of EPI in vascular tissue.

In conclusion, EPI infusion-site adverse events induced by FAP (or Proemend ${ }^{\circledR}$ ) infusion were analysed from the viewpoint of vascular tissue distribution of EPI and histological observation in the present study. The higher EPI concentrations in infusion-site vascular tissue and induction of severe adverse events such as inflammation and necrosis were observed when EPI was infused from the same site with FAP infusion. In contrast, infusion of EPI from different veins other than those used for FAP infusion resulted in lower vascular tissue concentrations of EPI and prevented the induction of inflammation and necrosis at the EPI infusion site in rats. In clinical practice, venous infusion of drugs should be performed from the other half of the body where breast cancer surgery is performed; the above findings suggest that the following administration methods are preferable: Infusion of EPI from a vein different from that used for FAP infusion (only for neoadjuvant chemotherapy), central venous catheter infusion of FAP and EPI, or oral AP and venous infusion of EPI.

\section{Acknowledgements}

Not applicable.

\section{Funding}

The present study was supported by research funds to promote the hospital functions of Japan Organization of Occupational Health and Safety.

\section{Availability of data and materials}

The dataset supporting the conclusions of the present study is included within the article.

\section{Authors' contributions}

MY, YM, KO and TM designed the study and analyzed the data. MY and KO performed experiments using rats. TN 
performed histological analysis. RK, SM, and MT participated in performing chemotherapy regimens. MY and TM wrote the manuscript. All authors read and approved the final manuscript.

\section{Ethics approval and consent to participate}

The chemotherapy for breast cancer patients with FAP infusion and FEC regimen or EC regimen was carried out at Chugoku Rosai Hospital (Kure, Hiroshima, Japan) according to the principles of the Declaration of Helsinki. This study protocol was approved by the ethics committee of Chugoku Rosai Hospital (approval no. 2016-01). Eight Japanese breast cancer patients ( 2 for EC regimen and 6 for FEC regimen) participated after providing written informed consent. The protocol of experiments using rats was reviewed and was approved by the Committee of Research Facilities for Laboratory Animal Sciences, Hiroshima International University (AE17-027).

\section{Patient consent for publication}

Patients provided written informed consent and agreed to the publication of their results.

\section{Competing interests}

The authors declare that they have no competing interests.

\section{References}

1. HeskethPJ,KrisMG,BaschE,BohlkeK,BarbourSY,Clark-SnowRA, Danso MA, Dennis K, Dupuis L, Dusetzina SB, et al: Antiemetics: American society of clinical oncology clinical practice guideline update. J Clin Oncol 35: 3240-3261, 2017

2. Rolia F, Molassiotis A, Herrstedt J, Aapro M, Gralla RJ, Bruera E, Clark-Snow RA, Dupuis LL, Einhorn LH, Feyer P, et al: 2016 MASCC and ESMO guideline update for the prevention of chemotherapy- and radiotherapy-induced nausea and vomiting and of nausea and vomiting in advanced cancer patients. Ann Oncol 27 (Suppl 5): v119-v133, 2016.

3. Berger MJ, Ettinger DS, Aston J, Barbour S, Bergsbaken J, Bierman PJ, Brandt D, Dolan DE, Ellis G, Kim EJ, et al: NCCN guidelines insights: Antiemesis, version 2.2017. J Natl Compr Canc Netw 15: 883-893, 2017.

4. Pritchett W and Kinsley K: Benefits and risks of fosaprepitant in patients receiving emetogenic regimens. Clin J Oncol Nurs 20: 555-556, 2016

5. Chow AY, Chin C, Dahl G and Rosenthal DN: Anthracyclines cause endothelial injury in pediatric cancer patients: A pilot study. J Clin Oncol 24: 925-928, 2006.

6. Ben Aharon I, Bar Joseph H, Tzabari M, Shenkman B, Farzam N, Levi M,ShalgiR, Stemmer SM and SavionN: Doxorubicin-induced vascular toxicity-targeting potential pathways may reduce procoagulant activity. PLoS One 8: e75157, 2013.

7. Bar-Joseph H, Stemmer SM, Tsarfaty I, Shalgi R and Ben-Aharon I: Chemotherapy-induced vascular toxicity-real-time in vivo imaging of vessel impairment. J Vis Exp: e51650, 2015.

8. Lundberg JD, Crawford BS, Phillips G, Berger MJ and Wesolowski R: Incidence of infusion-site reactions associated with peripheral intravenous administration of fosaprepitant. Support Care Cancer 22: 1461-1466, 2014.
9. Chau E, Lundberg J, Phillips G, Berger M and Wesolowski R: Updated report on incidence of infusion-site reactions associated with peripheral intravenous administration of fosaprepitant. J Oncol Pharm Pract: 1078155218769347, 2018.

10. Sato Y, Kondo M, Inagaki A, Komatsu H, Okada C, Naruse K, Sahashi T, Kuroda J, Ogura H, Uegaki S, et al: Highly frequent and enhanced injection site reaction induced by peripheral venous injection of fosaprepitant in anthracycline-treated patients. J Cancer 5: 390-397, 2014.

11. Lead AD, Kadakia KC, Looker S, Hilger C, Sorgatz K, Anderson K, Jacobson A, Grendahl D, Seisler D, Hobday T and Loprinzi CL: Fosaprepitant-induced phlebitis: A focus on patients receiving doxorubicin/cyclophosphamide therapy. Support Care Cancer 22: 1313-1317, 2014

12. Patel P, Leeder JS, Piquette-Miller M and Dupuis LL: Aprepitant and fosaprepitant drug interactions: A systematic review. $\mathrm{Br}$ J Clin Pharmacol 83: 2148-2162, 2017.

13. Mauri D, Pavlidis N and Ioannidis JPA: Neoadjuvant versus adjuvant systemic treatment in breast cancer: A meta-analysis. J Natl Cancer Inst 97: 188-194, 2005.

14. Tsuda T, Kyomori C, Mizukami T, Taniyama T, Izawa N, Horie Y, Hirakawa M, Ogura T, Nakajima T, Tsugawa K and Boku N: Infusion site adverse events in breast cancer patients receiving highly emetic chemotherapy with prophylactic anti-emetic treatment with aprepitant and fosaprepitant: A retrospective comparison. Mol Clin Oncol 4: 603-606, 2016.

15. Fujii T, Nishimura N, Urayama KY, Kanai H, Ishimaru H, Kawano J, Takahashi O, Yamauchi $\mathrm{H}$ and Yamauchi $\mathrm{T}$ : Differential impact of fosaprepitant on infusion site adverse events between cisplatin- and anthracycline-based chemotherapy regimens. Anticancer Res 35: 379-383, 2015.

16. Italia C, Paglia L, Trabattoni A, Luchini S, Villas F, Beretta L, Marelli G and Natale N: Distribution of 4'Epi-doxorubicin in human tissues. Br J Cancer 47: 545-547, 1983.

17. Camaggi CM, Strocchi E, Carisi P, Martoni A, Melotti B and Pannuti F: Epirubicin metabolism and pharmacokinetics after conventional- and high-dose intravenous administration: A cross-over study. Cancer Chemother Pharmacol 32: 301-309, 1993.

18. Robert J: Clinical pharmacokinetics of epirubicin. Clin Pharmacokinet 26: 428-438, 1994.

19. Chen R, Li J, Hu WW, Wang ML, Zou SL and Miao LY: Circadian variability of pharmacokinetics of cisplatin in patients with non-small-cell lung carcinoma: Analysis with the NONMEM program. Cancer Chemother Pharmacol 72: 1111-1123, 2013.

20. Murakami T and Yumoto R: Role of phosphatidylserine binding in tissue distribution of amine-containing basic compounds. Expert Opin Drug Metab Toxicol 7: 353-364, 2011.

21. Interview Form 'PROEMEND for intravenous infusion $150 \mathrm{mg}$ ', (March 2016). http://www.pmda.go.jp/.

22. Ottoboni T, Keller MR, Cravets M, Clendeninn N and Quart B: Bioequivalence of HTX-019 (aprepitant IV) and fosaprepitant in healthy subjects: A phase I, open-label, randomized, two-way crossover evaluation. Drug Des Devel Ther 12: 429-435, 2018.

23. Ottoboni T, Lauw M, Keller MR, Cravets M, Manhard K, Clendeninn N and Quart B: Safety of HTX-019 (intravenous aprepitant) and fosaprepitant in healthy subjects. Future Oncol 14: 2849-2859, 2018

24. Schwartzberg LS and Navari RM: Safety of polysorbate 80 in the oncology setting. Adv Ther 35: 754-767, 2018.

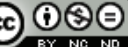

This work is licensed under a Creative Commons Attribution-NonCommercial-NoDerivatives 4.0 International (CC BY-NC-ND 4.0) License. 